\title{
On Effect of Soft Music on Learning English Language Vocabulary
}

\author{
Mojtaba Moradi \\ IAU, Shiraz Branch, Iran \\ Mostafa Zamanian \\ IAU, Shiraz Branch, Iran
}

\begin{abstract}
The aim of this paper is to search whether the use of soft music during studies improves student's learning of English language words, especially students learning and memorizing words in real-life situation .This study was conducted with 70 male intermediate EFL learners of 16-20, studying at Talash Language Institute (TLI), Kazeroun branch. A proficiency test was administered to show their homogeneity and equivalency. They were put into two groups namely: experimental group and control one .Four passages were used in this study, and the students were given an English passage with difficult words with their definitions written below. They were reading the passage and learning the words with their definitions while listening to soft music. This was pursued for four months. But each month the passage was a different one. The researcher applied the T-test to find out the differences, if any, between the two groups. The result showed that the students learned and memorized significantly better and more while accompanying with soft music.
\end{abstract}

Index Terms—soft music, intermediate level, EFL learners, proficiency test, control group, experimental group, T-test

\section{INTRODUCTION}

"Soft Music stabilizes mental, physical, and emotional rhythms to attain a state of deep concentration and focus in which large amounts of content information can be processed and learned Brewer (2005), and as Plato states "music is a moral law .It gives a soul to the universe, wings to the mind, flight to the imagination, a charm to sadness, and a life to everything". Jones (2005) states, "Much research has been devoted to the role soft music can play in developing or focusing the mind in learning English language words". Others suggest other techniques in the classroom. For computer time, studying and testing, it is suggested a CD played at a medium volume can relax and de-stress students. The volume should be low and it should create a filter for unwanted noise (Gourley, 2001).

The study also suggests that effectively incorporating soft music in an elementary classroom is a positive experience for children. "How is it that for most people music is a powerful part of personal life and yet when we go to work or school we turn it off?" (Brewer, 1995, p. 1). Soft music can be used for learning and memorizing the dialogue as well. It can also promote the attention, attitude and atmosphere. Soft music can welcome students into a classroom at the beginning of the day; help prepare students for a task, or transition children from one activity to another. It can be said that music have the tone for a lot of the activities that people participate (Giles, 1991). From shopping to eating to relaxing music is something that is used frequently to provide a backdrop for human activity. In short, music is of the power to enthuse or relax, produce a feeling of happiness or sadness, and even alter physiological states of heart rate and blood pressure (Giles, 1991).Special education teachers have used soft music to alter mood and assess emotional problems. Kids generally enjoy listening to music, singing, and humming. Music may effectively increase the capability to encounter the stress. Mixing literature with musical content helps to bring books alive and that musical classrooms encourage children to connect and take part in more activities. The need for music in both music rooms and regular education rooms is suggested (Giles 1991).

\section{THE PuRPose Of THE STUdY}

The aim of this paper is to search whether the use of soft music during studies improves students' learning of English language words. This will show the positive or negative effects that soft music elicits and make recommendations for use in the classroom. This study, therefore, seeks answers to the following question:

What are the effects of soft music on student's learning of English language words?

\section{RESEARCH QUESTIONS}

This study, therefore, seeks answers to the following question:

What are the effects of soft music on student's learning of English language words? 


\section{RESEARCH HYPOTHESES}

The present research has been conducted based on the above- mentioned hypothesis:

There is a very significant relationship between soft music and English language vocabulary learning.

\section{LITERATURE REVIEW}

As it has been seen and said many assumptions have been made in the past about the link between music and children's intellectual development. The "Mozart Effect" is a familiar term to the general public. "Many claims are made about music's value (or lack thereof) vis-a-vis intelligence, development, academic performance, and personality" (Costa-Giomi et al., 1999, p. 29). The volume of research regarding this topic yields differing opinions and results.

\section{A. Music Adds Emotional Content to Learning in Some Way, Thus Aiding Long Term Memory Retention}

Music is a way of building multi-sensory variety. It can act as a symbol of something else, as can stories, metaphors etc (Jensen, 1994). Also makes a suggestion to the learner - according to Lozanov, one cannot not suggest something to the learner, so maybe this is one way of suggesting something useful (BBLT p. 36).Eric Jensen (1997) says that most material can be set to music, written about in music, performed as rap or opera. He also said that music can be used as the key words to rewrite a familiar song or tune and then performed. (BBLT p. 187) This boosts understanding and meaning, by offering the material to students in different ways that they can get involved with. (Music here is alongside many other things like pictures, debates, etc) (Eric Jensen 1997).

"In other words, motivation and emotion can be triggered with no relationship to the instantaneous state of the environment and the actual response of the organism to it." He adds "We must seek a lead toward understanding the emotional response to music.” Roederer (in Clynes, 1982).

Goldstein (1998) at Stanford experimented with medical and music students. He had them listen to their favorite types of music, and gave them shots of the endorphin blocker naloxone, or a saline placebo. In this double blind study, a third of the listeners (those who had the blocker) reported less intense feelings than they usually got from music (Goldstein 1998). People tend to have the same emotional responses to music regardless of race or gender. (Reported in Jensen, 1994).

Film directors use music to enhance emotional response; for example Boorstin (1995): "Directors often think they won't use the music they spot, but they order it to be on the safe side. Unless they're in trouble, they're likely to tell themselves that the scene will play fins without it. Yet usually by the time is finished there is much more music than the director planned on, because once the music is in place the director realizes how much more juice it gives the scenes. It seems the right music makes us feel more intensely than we thought we could (Boorstin1995).

\section{B. Mood}

Music has a way of altering our current state of mood. We listen to music that makes us happy, motivates, encourages, energizes, focuses, and calms us. Music has an impact in our personal lives, so it would seem to be beneficial for use in the classroom to alter the moods of students in order to foster productive learning. Soft music, played while students are working, can create a welcoming environment which can set the mood for desired behavior, stabilize students' mental set, accelerate learning, and promote creativity.

When conducting an activity during a lesson, simply playing music while students are working, sets the desired mood. According to Brewer (2005), "The rhythms and tempo of musical sound can assist us in setting and maintaining our attention and focus by perking us up when we are weary and helping us find peace and calm when we are overenergized in some way" (11). If students are working in groups and certain individuals need to be enlivened, playing upbeat music can get students energized and motivated to participate. If students return from P.E hyper and need to quickly begin sustained silent reading, playing softer, slower, music can aid in soothing and calming students down in order to have them focus. Since music has the power to facilitate desired moods, it can have a positive impact on those students who have disorders.

\section{MethODOLOGY}

\section{A. Participants}

The participants in this study are 70 male intermediate EFL learners of 16-20, studying at Talash English language Institute, Kazeroun branch, Iran. And the reasons for the selection of the participants are that they are a part of the researcher's classroom, and they are at hand. So they will better reflex the processes they go through, while listening and learning the words.

\section{B. Instruments}

Four passages will be used in this study. The students are given an English passage of difficult words with their English definitions written below, while they are listening to soft music. The passages are taken from Internet, and the contents are about everyday issues. They are reading the passage and learning the words with their definitions, while 
listening to soft music. Of course, students were pre- tested to determine their homogeneity as well. This is pursued for four months, but each month the passage is a different one.

\section{Procedures}

In this study, a passage of everyday content was used to pre-test the 70 intermediate male EFL learners of English language words to show that they were of the same proficiency and were homogeneous. Then Four passages will be used in this study. The students are given an English passage of about 25 lines, and of at least 20 difficult words with their English definitions written below, while they are listening to soft music. The time allocated is 35 minutes. The passages are taken from Internet, and the contents are about everyday issues. They are reading the passage and learning the words with their definitions, while listening to soft music. Participants in the study will be divided into two groups, and both groups will receive the same passage per month, however the experimental group receives the treatment, that is listening to soft music during studying and learning the words, while the control group receives no treatment. Then next session, which is a five day interval, both groups will be given a questionnaire and the same passage but without definition, to choose the best choice given for each word. And later on, the questionnaires will be collected, analyzed and the results will be interpreted. This is pursued for four months, but each month the passage is a different one.

\section{DATA ANALYSIS}

When the raw data needed were gathered, the participants' responses of both groups in the two conditions namely, with music and without music were considered, and then mean scores, standard deviations, and standard error of measurements were shown. After that, a T-test was used to present the comparisons of the different conditions of the groups. A T-test was run to show the differences presented concerning the different conditions of both groups at the end and at the beginning of the work. Then ten comparisons were made and the results and information are indicated in the following paired sample test tables and graphs.

Paired Sample 1

As it is shown in table 1, the calculated $\mathrm{T}$ value shows that there is no statistically significant difference between the mean scores of pre -control group and the pre-experimental one. So the homogeneity and equality of the two groups are undoubtedly obvious.

TABLE 1

PAIRED SAMPLE T-TEST REFERRING TO THE PRE-TEST

\begin{tabular}{|l|l|l|l|l|}
\hline groups & $\mathrm{N}$ & Mean & Std. Deviation & Std. Error of Mean \\
\hline pre_control & 35 & 15.57 & 1.95968 & .33125 \\
\hline pre_experimental & 35 & 15.77 & 1.68184 & .28428 \\
\hline
\end{tabular}

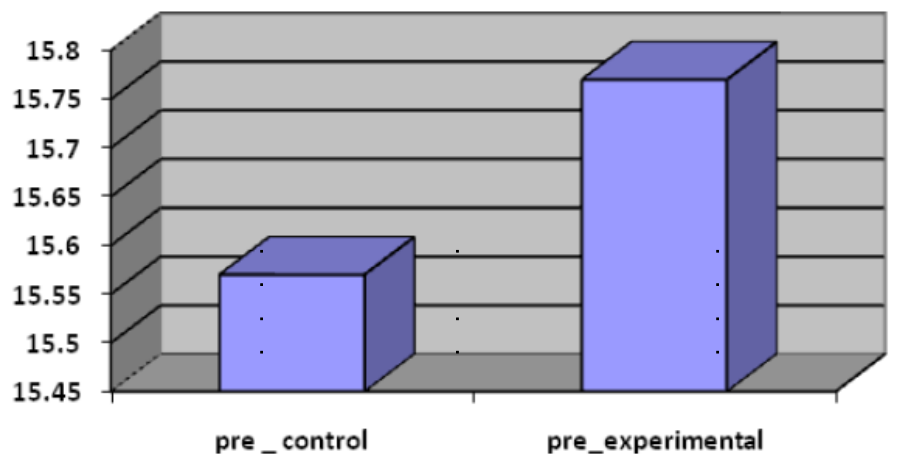

Paired Sample 2

As it is shown in table 2, the students' performance of the two groups is of statistically significant difference. That is to say, the mean score of the pre-experimental 1 receiving the treatment is significantly higher than that of the poscontrol 1 having no treatment. It shows that students better learn and memorize words in context while accompanying soft music.

TABLE 2.

PAIRED SAMPLE T-TEST REFERRING TO THE POST-TEST

\begin{tabular}{|l|l|l|l|l|}
\hline groups & $\mathrm{N}$ & Mean & Std. Deviation & Std. Error of Mean \\
\hline post_control_1 & 35 & 15.28 & .32169 & 1.90312 \\
\hline post_experimental_1 & 35 & 16.37 & 1.53557 & .25956 \\
\hline
\end{tabular}




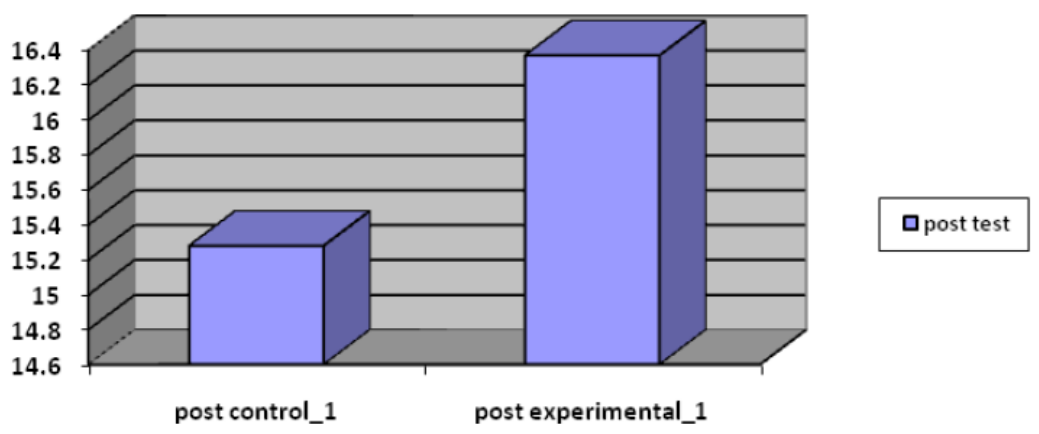

Paired Sample 3

Table 3, shows that the students' performance of the two groups is of statistically significant difference. In other words, the mean score of the pre-experimental 2 receiving the treatment is significantly higher than that of the poscontrol 2 having no treatment.

TABLE 3.

PAIRED SAMPLE T-TEST REFERRING TO THE POST-TEST

\begin{tabular}{|l|l|l|l|l|}
\hline groups & $\mathrm{N}$ & Mean & Std. Deviation & Std. Error of Mean \\
\hline post_control_2 & 35 & 15.40 & 1.76901 & .29902 \\
\hline post_experimental_2 & 35 & 16.60 & 1.63059 & .27562 \\
\hline
\end{tabular}

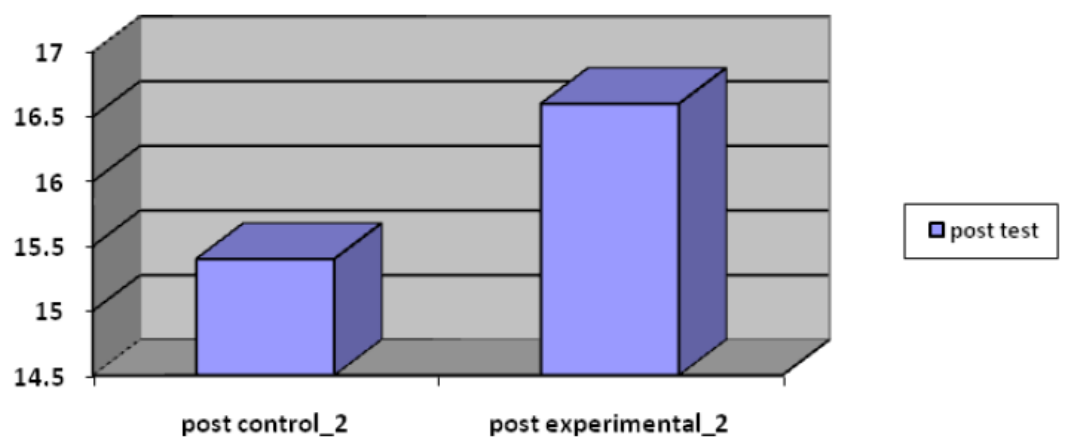

Paired Sample 4

Table 4, shows that the students' performance of the two groups is of statistically significant difference. In other words, the mean score of the pre-experimental 3 receiving the treatment is significantly higher than that of the poscontrol 3 having no treatment.

TABLE 4.

PAIRED SAMPLE T-TEST REFERRING TO THE POST-TEST

PAIRED SAMPLE T-TEST REFERRING TO THE POST-TEST
\begin{tabular}{|l|l|l|l|l|}
\hline groups & $\mathrm{N}$ & Mean & Std. Deviation & Std. Error of Mean \\
\hline post_control_3 & 35 & 15.34 & 1.71401 & .28972 \\
\hline post_experimental_3 & 35 & 16.57 & 1.42014 & .24005 \\
\hline
\end{tabular}

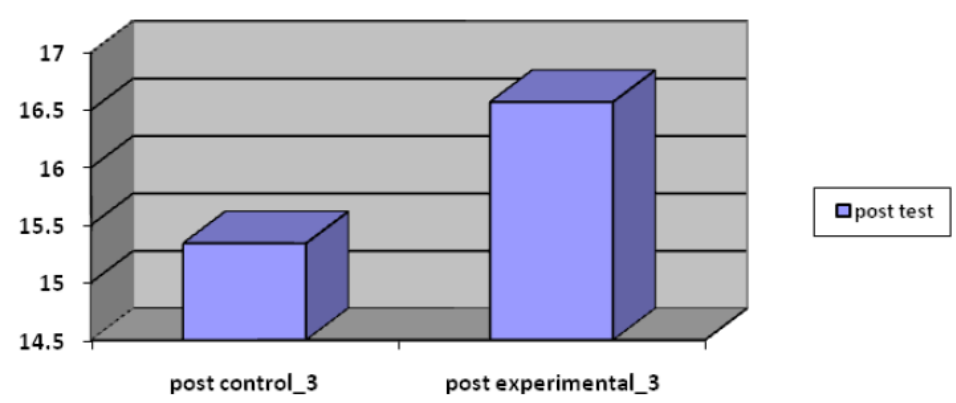

Paired Sample 5

Table 5 shows that there is a significant difference between the two groups. The post- control 4 and postexperimental 4 have the mean of (15.42) and (16.74) respectively. Having four times Post -testing of the students, the researcher has tried to have a more reliable result. 
TABLE 5 .

PAIRED SAMPLE T-TeST REFERRING TO THE POST-TEST

\begin{tabular}{|l|l|l|l|l|}
\hline groups & $\mathrm{N}$ & Mean & Std. Deviation & Std. Error of Mean \\
\hline post_control_4 & 35 & 15.42 & 1.55839 & .26342 \\
\hline post_experimental_4 & 35 & 16.74 & 1.37932 & .23315 \\
\hline
\end{tabular}

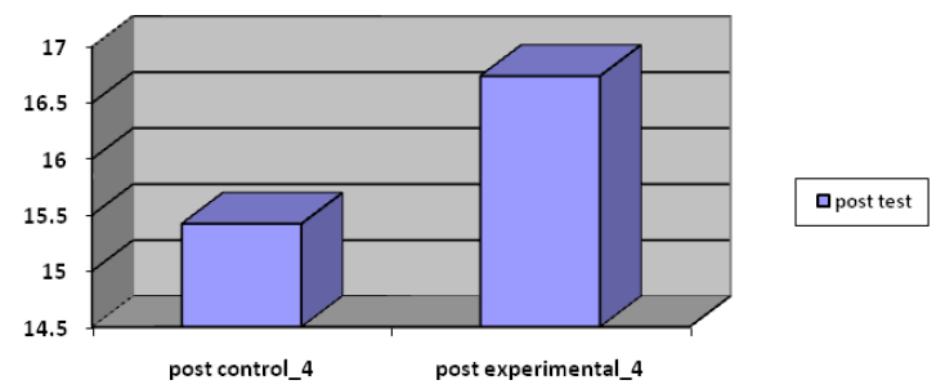

Paired Sample 6

Table 6 shows that the $\mathrm{T}$ value of pre- experimental and post- experimental 1 is statistically significant, therefore the students' performances are different and this difference is statistically significant. In other words, soft music enhances student's learning and memorizing of English language words as shown in post-experimenal1 with the mean score of (16.37) compared to that of the pre- experimental (15.77) while having no treatment.

TABLE 6.

PAIRED SAMPLE T-TEST 6

\begin{tabular}{|l|l|l|l|l|l|}
\hline group & N & Mean & Std. Deviation & Std. Error Mean & Sig. (2_tailed) \\
\hline pre_experimental & 35 & 15.77 & 1.68184 & .28428 & \multirow{2}{*}{0.005} \\
\hline post_experimental_1 & 35 & 16.37 & 1.53557 & .25956 & 0.56 \\
\hline
\end{tabular}

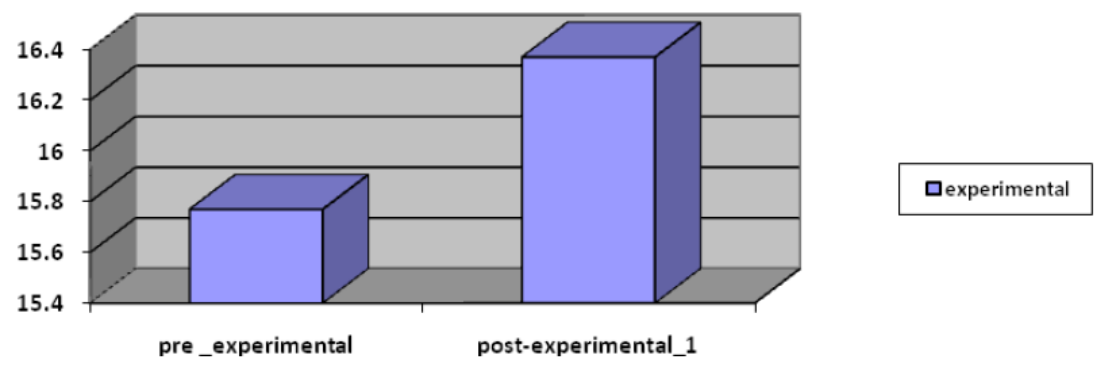

Paired Sample 7

In this part an independent sample T-test was used to show the differences between the performances of the control groups in pre-test (mean=15.57) and post-test (mean=15.28) on learning English language words. The table shows that there is no significant difference in the students' performances of the pre-control and post-control 1 tests.

TABLE 7.

PAIRED SAMPLE T-TEST 7

\begin{tabular}{|l|l|l|l|l|l|}
\hline groups & $\mathrm{N}$ & Mean & Std. Deviation & $\begin{array}{l}\text { Std. Error of } \\
\text { Mean }\end{array}$ & Sig. (2_tailed) \\
\hline pre_control & 35 & 15.57 & 1.95968 & .33125 & \multirow{2}{*}{0.016} \\
\hline post_control_1 & 35 & 15.28 & .32169 & 1.90312 & \\
\hline
\end{tabular}

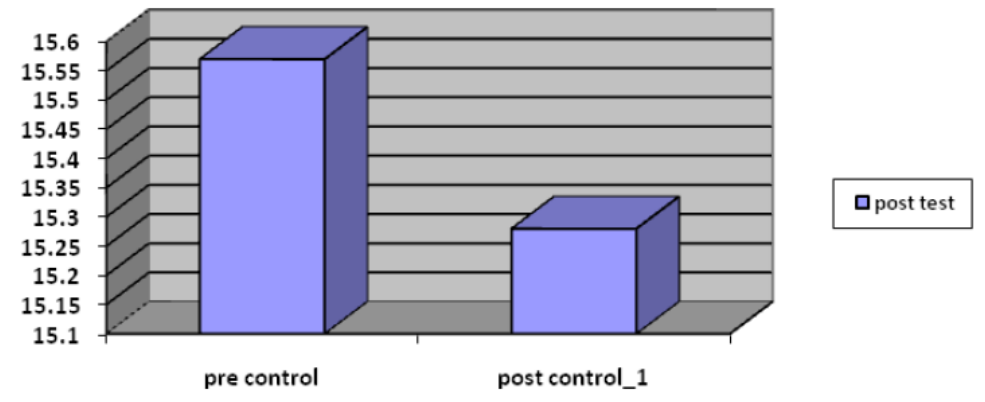

Paired Sample 8 
Table 8 indicates that there is a statistically significant difference between the post- control tests with the average mean of (16.07) and the post-experimental tests with the average mean of (16.57). It shows that words can be better learned while accompanying with soft music.

TABLE 8.

PAIRED SAMPLE T-TEST 8

\begin{tabular}{|l|l|l|l|l|}
\hline groups & $\mathrm{N}$ & Mean & Std. Deviation & $\begin{array}{l}\text { Std. Error of } \\
\text { Mean }\end{array}$ \\
\hline post_control 1.2.3.4 & 35 & 16.07 & 4.61287 & .77972 \\
\hline post_experimental 1.2.3.4 & 35 & 16.57 & 1.32783 & .22444 \\
\hline
\end{tabular}

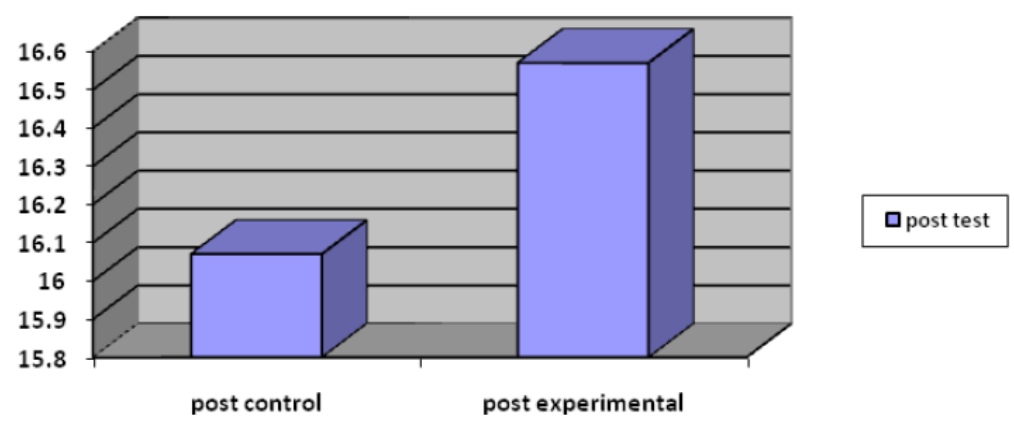

Paired Sample 9

Table 9. shows that there is a statistically significant difference between their pre-experimental test and postexperimental ones. As the result, soft music affects students' learning of English words.

TABLE 9.

PAIRED SAMPLE T-TEST 9

\begin{tabular}{|c|l|l|l|l|l|}
\hline & & & & Std. Error \\
groups & $\mathrm{N}$ & Mean & Std. Deviation & $\begin{array}{l}\text { Sig. } \\
\left(2 \_t a i l e d\right)\end{array}$ \\
\hline pre_experimental & 35 & 15.77 & 1.68184 & .28428 & 0.000 \\
\hline
\end{tabular}

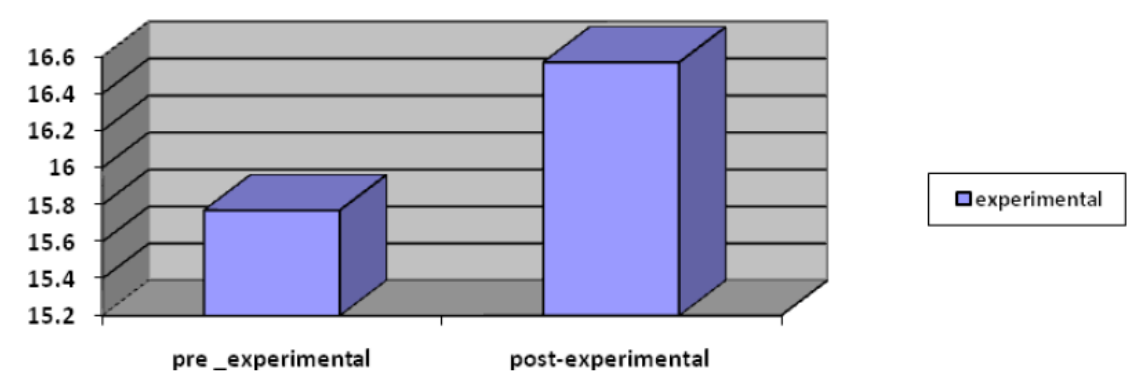

Paired Sample 10

Table10. indicates that there is no significant difference in the students' performances of pre-control test and postcontrol ones. Since they were given no treatment.

TABLE 10.

PAIRED SAMPLE T-TEST 10

\begin{tabular}{|l|l|l|l|l|l|}
\hline groups & $\mathrm{N}$ & Mean & Std. Deviation & $\begin{array}{l}\text { Std. Error of } \\
\text { Mean }\end{array}$ & Sig. (2_tailed) \\
\hline pre_control & 35 & 15.57 & 1.95968 & .33125 & .480 \\
\hline post_control 1.2.3.4 & 35 & 16.07 & 4.61287 & .77972 & .42 \\
\hline
\end{tabular}

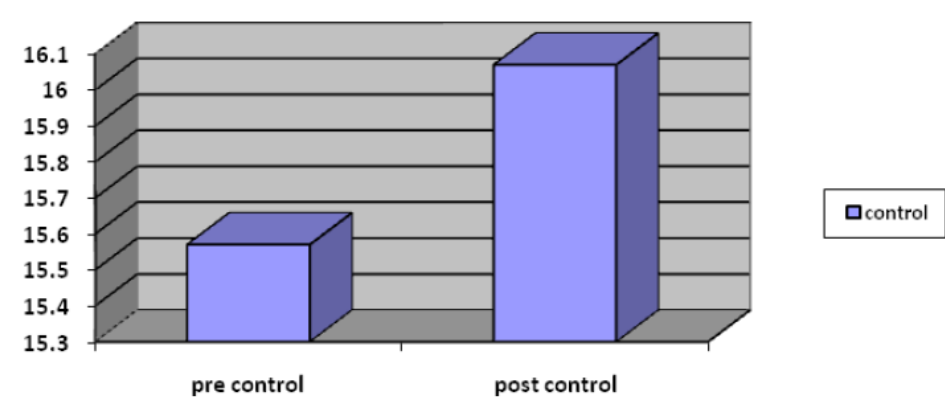




\section{DISCUSSION}

This section indicates the students' performances in different conditions namely, learning and memorizing words in contexts while soft music is played for post-experimental groups but it is absent for post-control ones. The study showed that there was no statistically significant difference between students' performances in pre-control and preexperimental ones, since they were given no treatment, but it revealed that the difference was statistically significant in post-experimental tests than those of post control ones. Since the former tests were accompanied with soft music, but nothing was played for the latter ones. It should be mentioned that the repetition of the post-experimental tests was merely to add to their reliability and statistical significance. And it shows that students better learn and remember words while soft music is played than the condition in which no music sound is present.

\section{CONCLUSIONS}

The researcher in this study tries to showthat whether the use of soft music improves and influences the student's learning of English words. This study shows that integrating soft music into an education classroom have beneficial qualities and the data collected indicates that students had positive behavior, during learning and memorizing words while they were listening to soft music. It also showed that soft music with the intent of creating a positive experience for students, promoted attention, positive attitude, and created a pleasant learning atmosphere. In addition, it recommends a continued use of soft music during learning, memorizing, and even remembering words. Although music can distract the students' minds as well. Since learners may get to excited or sensational or get habitual with it. After all. Music, especially soft one can be a way of overcoming the difficulties in focusing on and attending in situations brimmed with noises and extra voices.

\section{REFERENCES}

[1] Abeles, H., Hoffer, C., \& Klotman, R. (1994). Foundations of music education. New York: Shirmer Books.

[2] Allen, R. "Music as One of Your Classroom Strategies." Songs for Teaching: Using Music to Promote Learning. 2002-2008.

[3] Bangerter, Adrian, \& Heath, Chip (2004). The Mozart effect: Tracking the evolution of a scientific legend. The British Journal of Social Psychology, 43, 605-623.

[4] Rubin, \& Rebecca B. (2007). Does Listening to Mozart Affect Listening Ability? The International Journal of Listening, 21(2), 124-139.

[5] Brewer, C. B. (1995). Music and learning: Integrating music in the classroom. Toronto: Zephyr Press. Retrieved, March 3, 2008, from http://www.newhorizons.org/strategies/arts/brewer.htm.

[6] Brutten, S. R., Angelis, P. J., \& Perkins, K. (1985). Music and memory: Predictors for attained ESL oral proficiency. Language Learning, 35, 299-313.

[7] Caldwell, G.N., \& Riby, L.M. (2006) .The Effects of Music Exposure and Own Genre Preference on Conscious and Unconscious Cognitive Processes: A Pilot ERP Study. Consciousness and Cognition,16, 992-996. Retrieved March 3, 2008, from http://www.sciencedirect.com.

[8] Chalmers, L., \& Olson, M. R., \& Zurkowski, J.K. (1999). Music as a Classroom Tool. Intervention in School and Clinic, 35, 43-45.

[9] Clark, M. E., McCorkel, R. R., \& Williams,S. (1981). Music therapy-assisted labor and delivery. Journal of Music Therapy, 18, 88-100.

[10] Gourley, C., (2001). How Does Music Change Your Mood? Teacher's Edition, 23(4). Retrieved March 3, 2008, from Education Research Complete database.

[11] Hallam, S. \& Price, J. \& Katsarou, G. (2008). "The Effects of soft Music on Primary School Pupils' Task Performance." Educational Studies. 28. p111-122. Retrieved March 24, 2008, from Academic Search Premier. EBSCO Host. SUNY Potsdam Library Database, NY. 15 March 2008 http://search.epnet.com/path: search; the effects of background music;

[12] Ivanov V.K. \& Geake, J.G. (2003). The Mozart Effect and Primary School Children. Psychology of Music, 31(4), 405-413.

[13] Jensen, E. (2002). Implementing Music in the Classroom. Retrieved March 3, 2008, from http://www.songsforteaching.com/ericjensen/1.htm.

[14] Jones, W.P. (2005). Music, the Brain, and Education. Montessori Life. Retrieved March 24, 2008, from http://ebsco.potsdam.edu.

[15] Levy, Yiftach. (1986) “The Effects of calm Music on Learning:" Effect of music on learning.

[16] Miranda, E. R. (2003). .Computational Models of Music. Digitial Music Online Tutorials.

[17] Nantais, K.M. \& Schellenberg. (1999). The Mozart Effect: An Artifact of Preference. American Psychological Society, 10 (4). 370-373.

[18] Rauscher, F.H. \& Shaw, G. L. \& Ky, K.N. (1993). Music and Spatial Task Performance. Nature, 365, 611.

[19] Schellenberg, E.G., (2005). Music and Cognitive Abilities. American Psychology Society, 14 (6), 317-320.

[20] Sze, S. \& Yu, S. (2004). Effects of Music Therapy on Children with Disabilities. International Conference on Music Perception and Cognition.

[21] Towell, H.T. (2000). Teaching Reading: Motivating Students through Music and Literature.

[22] Weinberger, N.M. (2000). Music and the Brain: A broad Perspective. Music Educators Journal, 87 (2), 8-10.

[23] Weinberger, N. M. (1998). The music in our minds. Educational Leadership, 56 (3), 36 - 40. 
Mojtaba Moradi is a Ph.D student in TEFL from the IAU, Qeshm Branch, Iran.

Mostafa Zamanian holds a Ph.D (from U.S.A) and he is the chairman of M.A and Ph.D program in English. IAU, Shiraz Branch, Iran. 